\title{
COBERTURA PLÁSTICA SOBRE O VINHEDO E SUAS INFLUÊNCIAS NAS CARACTERÍSTICAS FÍSICO-QUÍMICAS DO MOSTO E DO VINHO ${ }^{1}$
}

\author{
GERALDO CHAVARRIA ${ }^{2}$, HENRIQUE PESSOA DOS SANTOS ${ }^{3}$, MAURO CELSO ZANUS $^{4}$, \\ GILMAR ARDUIINO BETTIO MARODIN ${ }^{5}$, CRISTIANO ZORZAN ${ }^{6}$
}

RESUMO - O objetivo deste trabalho foi avaliar a influência da cobertura plástica tipo ráfia de $160 \mu \mathrm{m}(\mathrm{CP})$ sobre as características físico-químicas do mosto e do vinho da cultivar Moscato Giallo, em duas colheitas realizadas nas safras de 2006 e 2007, com experimento em delineamento completamente casualizado, em vinhedo da cultivar Moscato Giallo, delimitando-se áreas com cobertura plástica impermeável e sem cobertura, como controle. Os vinhos foram elaborados por meio de microvinificações $(20 \mathrm{~L})$, tendo-se três repetições para cada área. Foram realizadas avaliações físico-químicas do mosto ( ${ }^{\circ}$ Brix, açúcares redutores, densidade, acidez total, ácido tartárico, ácido málico e pH) e do vinho (densidade, graduação alcoólica, acidez total, acidez volátil, $\mathrm{pH}$, extrato seco, açúcares redutores, cinzas, índice 420, compostos voláteis e minerais). Com a diminuição da radiação solar, as uvas sob cobertura plástica maturam em um período mais prolongado que no cultivo ausente de cobertura. As uvas produzidas sob cobertura plástica apresentam maior rendimento de mosto. Porém, apresentam menor concentração de açúcares. Os vinhos produzidos com uvas provenientes de videiras cobertas apresentam menor graduação alcoólica. Por outro lado, há redução dos teores de acetato de etila e acidez volátil. O prolongamento da maturação das uvas sob cobertura plástica determina atraso na data de colheita, para que seja atingida a mesma concentração de açúcar no mosto e graduação alcoólica no vinho proveniente de videiras sem cobertura.

Termos para indexação: Vitis vinifera, plasticultura, microclima, qualidade enológica.

\section{PLASTIC COVER USE AND ITS INFLUENCES ON PHYSICAL-CHEMICAL CHARACTERISTICS IN MUST AND WINE}

\begin{abstract}
The aim of this study was to evaluate plastic overhead covering (POC) influence on must and wine of Moscato Giallo cultivar. In two harvests the 2006 and 2007 vintages an experiment was carry out in a completely randomized design. It was performed in a vineyard covered with an impermeable plastic cloth and without covering as control. From each vineyard, three microvinification $(20 \mathrm{~L})$ were elaborated. Physico-chemical analysis of musts ( ${ }^{\circ}$ Brix, reduce sugar content, density, total acidity, tartaric acid, malic acid e $\mathrm{pH}$ ) and wines (density, alcohol degree, acidity, volatile acidity, $\mathrm{pH}$, dry extract, reduce sugar content, ashes, 420 index, volatile compounds and minerals) were analyzed. According to results POC (raffia type with $160 \mu \mathrm{m})$ grapes showed more yield must. However due to delay maturation showed lower sugar concentration. Wine produced with POC grapes had lower alcohol graduation. Another hand, the better sanity of grapes resulted in lower tenors of ethyl acetate and volatile acidity. POC system demands delay in harvest to achieve the same sugar concentration and alcohol graduation compared to grapes from open sky. Index terms: Vitis vinifera, plasticulture, microclimate, enological quality.
\end{abstract}

\footnotetext{
1'(Trabalho 173-10). Recebido em: 30-07-2010. Aceito para publicação: 15-03-2011.

${ }^{2}$ Eng. Agr ${ }^{\circ}$ Dr. Professor Fisiologia das Plantas Cultivadas, Universidade de Passo Fundo, CEP 99001-970, Passo Fundo-RS. E-mail: geraldochavarria@upf.br

${ }^{3}$ Eng. Agr ${ }^{\circ}$ Dr. Pesquisador Embrapa Uva e Vinho, CEP 95700-000, Bento Gonçalves-RS. E-mail: henrique@cnpuv.embrapa.br ${ }^{4}$ Eng. Agr ${ }^{\circ}$ M.Sc. Pesquisador Embrapa Uva e Vinho, CEP 95700-000, Bento Gonçalves-RS. E-mail: zanus@cnpuv.embrapa.br ${ }^{5}$ Eng. Agr ${ }^{\circ}$ Professor Dr. Departamento de Horticultura, Universidade Federal do Rio Grande do Sul, CEP 91540-000, Porto AlegreRS. E-mail: marodin@ufrgs.br

${ }^{6}$ Enólogo Bolsista DTI - Embrapa Uva e Vinho, CEP 95700-000, Bento Gonçalves-RS. E-mail: zorzan@cnpuv.embrapa.br; Bolsista CNPq.
} 


\section{INTRODUÇÃO}

Na Serra Gaúcha, o período de maturação das uvas é caracterizado pelo excesso de chuvas, que prejudicam a qualidade das uvas devido à incidência de doenças fúngicas (SÔNEGO et al., 2005).

Em função desta problemática, a utilização da cobertura plástica impermeável sobre as linhas de cultivo vem tornando-se uma alternativa viável, tanto no cultivo de uvas de mesa, quanto na obtenção de uvas destinadas à vinificação (CHAVARRIA et al., 2007). Essa cobertura propicia alterações no microclima da videira, diminuindo a água livre sobre folhas e cachos (CARDOSO et al., 2008) e isto faz com que a incidência e a severidade de doenças, como podridões de cachos, sejam diminuídas, uma vez que, pela ausência da água, o processo de infecção não ocorre (CHAVARRIA et al., 2007). Entretanto, embora se conheça a potencialidade da cobertura plástica sobre a diminuição das doenças e a garantia do potencial produtivo, e já exista literatura demonstrando tais benefícios (CHAVARRIA et al., 2009), ainda se dispõe de poucas informações sobre o efeito desta tecnologia na qualidade do mosto e final dos vinhos.

A hipótese do trabalho baseia-se no fato de a cobertura plástica impermeável influenciar drasticamente no microclima do vinhedo, influindo na sanidade e na fisiologia das videiras, que, por sua vez, refletem na uva, e esta, por sua vez, altera a composição físico-química do mosto e, consequentemente, o vinho oriundo deste sistema de cultivo. Desta forma, o objetivo deste trabalho foi avaliar o efeito da cobertura plástica sobre o mosto e a qualidade do vinho da cultivar Moscato Giallo.

\section{MATERIAL E MÉTODOS}

O experimento foi conduzido em colheitas anuais, nas safras de 2006 e 2007, em vinhedo localizado no distrito de Mato Perso (latitude $29^{\circ} 06^{\prime} \mathrm{S}$, longitude $51^{\circ} 20^{\prime} \mathrm{O}$ e altitude de $541 \mathrm{~m}$ ), município de Flores da Cunha - RS, composto de videiras da cultivar Moscato Giallo (clone VCR1), enxertadas sobre porta-enxerto 'Kober 5BB' e plantadas em espaçamento de $3,0 \mathrm{~m}$ x $0,9 \mathrm{~m}$, perfazendo 3.703 plantas por hectare, conduzidas em sistema de cultivo "Y", com fileiras de 35 metros na direção nordestesudoeste, com poda mista, deixando-se varas de 6-8 gemas e esporões de duas gemas.

$\mathrm{O}$ vinhedo foi dividido em duas áreas. A primeira (A1), constituída por 12 fileiras cobertas na linha de cultivo com lonas plásticas trançadas de polipropileno transparentes, impermeabilizadas com polietileno de baixa densidade, com $160 \mu \mathrm{m}$ de espessura e largura de 2,65 m. Na segunda, cinco fileiras foram mantidas descobertas, e as linhas centrais foram consideradas como plantas-controle (A2).

Para a elaboração dos vinhos, foram colhidas aleatoriamente, em 10 plantas de cada uma das áreas, três amostras de $28 \mathrm{~kg}$ de uva nas colheitas das safras de 2006 em período único (02-03-06 - Pu) e 2007 em dois períodos (12-02-07 - P1 e 22-02-07 - P2). Os tratamentos $(\mathrm{T})$ foram constituídos de seis combinações: T1 (A1:Pu); T2 (A2:Pu); T3 (A1:P1); T4 (A2:P1); T5 (A1:P2) e T6 (A2:P2).

Após colhidas, as uvas foram desengaçadas, esmagadas e prensadas, recolhendo-se alíquota de $100 \mathrm{~mL}$ em cada repetição do mosto, com a finalidade de realização das análises. O restante de cada mosto foi colocado individualmente em recipientes de vidro, com capacidade de $20 \mathrm{~L}$, que foram fechados com válvulas de Müller, de maneira que a fermentação do mosto se processasse em condições anaeróbias em sala com temperatura controlada de $20^{\circ} \mathrm{C}$.

Em cada recipiente, foram adicionados $80 \mathrm{mg} \mathrm{L}^{-1}$ de $\mathrm{SO}_{2}$ e $0,03 \mathrm{~mL} \mathrm{~kg}^{-1}$ de enzima pectolítica (Rohavin $^{\circledR}$ LX) e encaminhados para decantação durante 24 horas a $0^{\circ} \mathrm{C}$. Após a trasfega (sifonagem) para separação das borras, formadas durante a clarificação, foi adicionada levedura seca ativa (Saccharomyces cerevisiae - Embrapa $1 \mathrm{vvt}$ ) na proporção de $0,2 \mathrm{~g} \mathrm{~L}^{-1}$ de mosto. Os mostos não foram chaptalizados.

Quando concluída a fermentação alcoólica do vinho, constatada pela análise da concentração de açúcar residual e pelo desprendimento de dióxido de carbono, foi feita uma trasfega a fim de separar o vinho da borra. Para a clarificação protéica, foi adicionado $1 \mathrm{~g} \mathrm{~L}^{-1}$ de bentonite (montmorilonita absorvente), previamente hidratada durante 22 horas, em 20 partes de água. A estabilização tartárica do vinho foi realizada a uma temperatura de $-3^{\circ} \mathrm{C}$, durante 21 dias, para posteriormente ser engarrafado e conservado a $16^{\circ} \mathrm{C}$.

Mosto e vinho de cada tratamento foram, então, analisados nos laboratórios de Enoquímica e de Instrumentação da Embrapa Uva e Vinho. O teor de sólidos solúveis totais ( ${ }^{\circ}$ Brix) foi obtido pela leitura em um refratômetro de bancada, com correção automática de temperatura, marca Amercian Optical, modelo 10460. A densidade foi determinada por meio de densímetro digital marca Anton Paar, modelo DMA-45; o álcool $\left(\% \mathrm{v} / \mathrm{v}\right.$ a $\left.20^{\circ} \mathrm{C}\right)$, determinado por destilação e leitura no mesmo densímetro (MIELE; RIZZON, 2006), a acidez total (meq L ${ }^{-1}$ ), pela titulação do vinho com $\mathrm{NaOH} 0,1 \mathrm{~N}$, utilizando azul de bromotimol como indicador; a acidez volátil (meq L-1), pelo arraste de vapor com titulação do vinho com 
$\mathrm{NaOH} 0,1 \mathrm{~N}$ e fenolftaleína como indicador; e o pH, com um potenciômetro digital, marca Corning, modelo 125, equipado com elétrodo de vidro e calibrado com solução-padrão de pH 3,0 e pH 4,0 (MIELE; RIZZON, 2006).

Os açúcares redutores e o extrato seco foram determinados segundo metodologia utilizada por Rizzon e Miele (2001); as cinzas, pela incineração de $20 \mathrm{~mL}$ de vinho em cadinhos de platina a $530-550^{\circ} \mathrm{C}$ (MIELE; RIZZON, 2006) e o índice 420, medindose a absorbância com espectrofotômetro a $420 \mathrm{~nm}$, marca Perkin-Elmer, modelo Lambda 3 (MIELE; RIZZON, 2006).

A análise dos minerais $\mathrm{Ca}, \mathrm{Mg}, \mathrm{Fe}, \mathrm{Cu}$ e $\mathrm{Zn}$ presentes no vinho foi realizada através de absorção atômica, utilizando-se de um espectrofotômetro de absorção atômica Perkin-Elmer, modelo 2380, enquanto o K, Na e Rb por emissão de chama, e P por colorimetria (MENEGUZZO et al., 2006).

Os dados obtidos foram sumetidos à análise estatística de variância (ANOVA); e as médias, comparadas pelo teste de Tukey, a $5 \%$ de probabilidade de erro.

\section{RESULTADOS E DISCUSSÃO}

Foi observado diferença significativa em relação ao rendimento do mosto durante o processamento (prensagem), sendo este superior em 7 e $8 \%$ nas uvas provenientes da A1, nas respectivas safras de 2006 e 2007 (Tabela 1). Este maior rendimento, possivelmente, tenha relação direta com a maior massa individual e o conteúdo de água das bagas sob cobertura plástica.

A análise físico-química do mosto na Pu destacou que a A1 propiciou menor densidade e menor quantidade de açúcares redutores (Tabela 1). Estes resultados complementam a ideia de que as uvas da cultivar Moscato Giallo não alcançaram o mesmo estádio de maturação das uvas A2, no momento da colheita (Tabela 1). Isto se refletiu em menor graduação alcoólica e maior acidez total nos vinhos A1, na safra de 2006 (Tabela 2).

Este atraso na maturação da uva deve-se à interferência que a cobertura exerce sobre este processo fisiológico, estendendo o período de maturação a partir da mudança de cor das bagas até a colheita, possivelmente pela diminuição da radiação solar (CHAVARRIA et al., 2008a). Isto implica a necessidade de atrasar a data de colheita das uvas cultivadas sob cobertura plástica, a fim de propiciar a máxima maturação fisiológica e tecnológica. Este procedimento é possível neste sistema de cultivo devido à garantia fitossanitária que a cobertura plástica propicia ao vinhedo.

Na P1 da safra de 2007, o mosto A1 apresentou-se distinto do cultivo descoberto somente em relação ao maior nível de acidez total (Tabela 1). Contudo, na segunda colheita, este mosto apresentou maior concentração de ácido tartárico, seguindo a tendência da primeira colheita, embora esta não tenha sido significativa. Portanto, o atraso da colheita nesta safra favoreceu a redução da acidez e o pH do mosto (Tabela 1).

A acidez condiciona a estabilidade biológica (ausência de microrganismos que prejudiquem a fermentação), a cor e as características gustativas dos vinhos (RIZZON et al., 1998). A acidez do mosto e do vinho pode ser avaliada através da determinação do $\mathrm{pH}$, da acidez total e da concentração individual dos ácidos orgânicos (RIZZON et al., 1998). As concentrações destes ácidos estão relacionadas com aspectos fisiológicos da maturação e as características de solo, clima e práticas agronômicas (RIZZON; SGANZERLA, 2007). De acordo com os resultados obtidos nas avaliações de mosto, a cobertura plástica não afetou a acidez total e a concentração dos ácidos tartárico e málico do mosto, embora o pH tenha sido menor (Tabela 1). Esta diminuição do $\mathrm{pH}$ pode ter sido afetada pela menor quantidade de cátions de potássio, como descrito por Rizzon et al. (1998).

Considerando, em conjunto, o acúmulo de açúcares e a degradação dos ácidos orgânicos, podese sugerir que as taxas de incremento de açúcar nas bagas sejam menores que as de degradação de ácidos orgânicos, já que os níveis dos ácidos no mosto tiveram comportamento diferenciado, se comparados ao cultivo descoberto (Tabela 1). A degradação do ácido málico pelo aumento da temperatura do ar pode justificar a similaridade em acidez da uva, apesar das diferenças de acúmulo de açúcares (Tabela 1). Contudo, o acúmulo de açúcar tem influência diretamente não só da temperatura, mas também da radiação solar (MULLINS et al., 1992). E como a cobertura restringiu em até $56,45 \%$ a radiação no nível dos cachos, isto pode justificar o decréscimo na taxa de incremento de açúcar ao longo da maturação.

$\mathrm{O}$ atraso na maturação sob a cobertura, na safra de 2006, também se refletiu na concentração de álcoois superiores do vinho, sendo a soma total significativamente menor em relação ao cultivo descoberto (Tabela 3). Isto, se deve à menor disponibilidade de açúcares nas uvas cobertas, pois são parâmetros químicos diretamente relacionados (JACKSON, 2000).

$\mathrm{O} \mathrm{pH}$ é uma das características mais importantes do vinho, pois, além de interferir na cor, exerce efeito pronunciado sobre o gosto. Vinhos 
com pH elevado são mais suscetíveis às alterações oxidativas e biológicas, uma vez que o teor de dióxido de enxofre ativo é proporcionalmente menor (AERNY, 1985). O pH dos vinhos do tratamento coberto foi significativamente inferior nas safras de 2006, 2007(1) e 2007(2), conforme foi observado no mosto, nas safras de 2006 e 2007 (2) (Tabela 1). A maior acidez total e o menor $\mathrm{pH}$ dos vinhos, na safra de 2006 do tratamento coberto, podem ser atribuídos ao menor conteúdo de potássio dos mostos (Tabela 4 ), pois quanto menor a quantidade desse mineral, menor a precipitação do ácido tartárico na forma de bitartarato de potássio durante a vinificação (BOULTON, 1980; RIZZON et al., 1998). Contudo, nas demais safras, não foram observadas diferenças em relação à concentração de minerais entre as áreas com e sem cobertura.

A quantidade de minerais no vinho pode ser influenciada por fatores como a fertilidade do solo, as práticas de fertilização, o estado hídrico da planta e as condições de vinificação (MAARSE et al., 1987; MASLE et al., 1992). De acordo com os resultados obtidos na safra de 2006, no vinho da área coberta foram observadas quantidades significativamente menores de $\mathrm{Mg}, \mathrm{Na}, \mathrm{Mn}, \mathrm{Rb}$ e, principalmente, de $\mathrm{P} \mathrm{e} \mathrm{K}$ (Tabela 4). Estes menores teores de minerais são também confirmados pela menor concentração de cinzas no vinho (Tabela 3 ).

Como estes resultados não foram confirmados na safra de 2007, destacando-se que não houve correção de adubação de uma safra para a outra, sugere-se que, apesar de o microclima sob a cobertura restringir o consumo de água, favorecendo melhor aporte hídrico para a planta, outro fator a ser considerado nas diferenças em concentrações de minerais na baga é o fato de a cobertura condicionar concentração de água superficial $(0-30 \mathrm{~cm})$ apenas na região de entrelinha (CHAVARRIA et al., 2008c). Em função disto, as coberturas propiciam uma redistribuição do sistema radicial da região da linha para a entrelinha. Como a primeira safra foi realizada aos dois anos após o início da cobertura, o sistema radicular poderia não estar completamente alocado na entrelinha, influenciando a absorção de minerais.

$\mathrm{O}$ extrato seco dos vinhos da área coberta foi significativamente inferior nas duas colheitas realizadas na safra de 2007, enquanto não foram observadas diferenças entre os tratamentos no ano de 2006 (Tabela 2). Na safra de 2006, assim como na segunda colheita de 2007, os vinhos sob cobertura plástica também apresentaram valores inferiores nas análises de cinzas (Tabela 2).

Os valores de acidez volátil do vinho foram de 3,3 e 8,0 meq $\mathrm{L}^{-1}$ na safra de 2006 para as áreas coberta e descoberta, respectivamente (Tabela 2). Estes menores valores de acidez volátil alcançados no vinho da área coberta estão associados à maior sanidade das uvas, as quais apresentaram menor incidência e severidade de podridões de cacho, sobretudo de podridão ácida, que é a principal causadora deste defeito no vinho (CHAVARRIA et al., 2008b). Isto também foi comprovado pela significativa redução de acetato de etila no vinho da área coberta nas três safras em relação à descoberta (Tabela 3).

Na safra de 2006, diferentemente das demais safras estudadas, o índice 420 foi menor nos vinhos sob cobertura plástica, indicando que estes apresentaram menor intensidade de cor amarela (Tabela 2). Isto demonstra que estes vinhos apresentaram menor quantidade de oxidações, possivelmente devido à sanidade das uvas. Desta forma, vinhos brancos e jovens, produzidos com uvas com maiores quantidades de podridões de cacho, poderão apresentar um índice 420 mais elevado (JACKSON, 2000). Contudo, nas duas colheitas da safra de 2007, as uvas sob cobertura tinham menor incidência de podridões de cacho, o que aponta que tal diferença no índice 420 tenha sido afetada pelo nível de maturação diferenciada da área descoberta. Estádios de maturação mais avançados também podem estar associados a colorações mais intensas (MENEGUZZO et al., 2006), sendo que as uvas da área descoberta estavam mais maduras se comparadas às da área coberta.

A melhor condição fitossanitária, propiciada pela cobertura, é importante para as uvas brancas, como a cultivar Moscato Giallo, as quais apresentam maior sucetibilidade às podridões de cachos (SÔNEGO et al., 2003). Sendo assim, a melhoria da sanidade das uvas destaca-se como uma das grandes contribuições que o cultivo de videiras sob cobertura plástica possa propiciar. Sob o ponto de vista técnico, é uma alternativa na busca do incremento da qualidade dos vinhos em regiões que apresentam excesso de chuvas no período da maturação, exemplificada pela "Serra Gaúcha".

É oportuno destacar, também, que vinhos espumantes podem ser grandemente beneficiados pelo uso da cobertura plástica, considerando que é desejável que as uvas para o processamento destes tipos de vinhos sejam colhidas com acidez mais elevada e menor quantidade de açúcares. Desta maneira, a cobertura não interfere negativamente na desacidificação do vinho, o que pode ocorrer em situações em que a uva permanece por um período superior de maturação, mas, sim, imprime o seu melhor benefício, que é a obtenção de uvas sadias devido às características microclimáticas favoráveis ao controle de doenças fúngicas. 
TABELA 1 - Composição química de mostos na colheita da cultivar (Vitis vinifera L.) Moscato Giallo conduzida em "Y", cultivada com cobertura plástica (A1) e sem cobertura (A2), na colheita das safras de $2006(\mathrm{Pu})$ e em 2007, precoce (P1) e tardia (P2). Flores da Cunha-RS.

\begin{tabular}{lcccccc}
\hline \multirow{2}{*}{ Análises } & \multicolumn{2}{c}{ Safra 2006 $(\mathrm{Pu})$} & \multicolumn{2}{c}{ Safra $2007(\mathrm{P} 1)^{* *}$} & \multicolumn{2}{c}{ Safra $2007(\mathrm{P} 2)^{* *}$} \\
\cline { 2 - 7 } & $\begin{array}{c}\text { Coberto } \\
(\mathrm{A} 1)\end{array}$ & $\begin{array}{c}\text { Descoberto } \\
(\mathrm{A} 2)\end{array}$ & $\begin{array}{c}\text { Coberto } \\
(\mathrm{A} 1)\end{array}$ & $\begin{array}{c}\text { Descoberto } \\
(\mathrm{A} 2)\end{array}$ & $\begin{array}{c}\text { Coberto } \\
(\mathrm{A} 1)\end{array}$ & $\begin{array}{c}\text { Descoberto } \\
(\mathrm{A} 2)\end{array}$ \\
\hline SST $\left({ }^{\circ}\right.$ Brix) & $17,5 \mathrm{bB} *$ & $19,0 \mathrm{aA}$ & $18,4 \mathrm{aAB}$ & $19,1 \mathrm{aA}$ & $19,1 \mathrm{aA}$ & $19,1 \mathrm{aA}$ \\
Açúcares redutores $\left(\mathrm{g} \mathrm{L}^{-1}\right)$ & $182,0 \mathrm{bA}$ & $197,3 \mathrm{aA}$ & $171,7 \mathrm{aA}$ & $179,2 \mathrm{aB}$ & $179,3 \mathrm{aA}$ & $179,5 \mathrm{aB}$ \\
Densidade & $1,075 \mathrm{bA}$ & $1,082 \mathrm{aB}$ & $1,076 \mathrm{aA}$ & $1,079 \mathrm{aB}$ & $1,079 \mathrm{bA}$ & $1,320 \mathrm{aB}$ \\
Acidez total $\left(\mathrm{meq} \mathrm{L}^{-1}\right)$ & $74,0 \mathrm{aB}$ & $76,0 \mathrm{aA}$ & $89,3 \mathrm{aA}$ & $77,3 \mathrm{bA}$ & $73,3 \mathrm{aB}$ & $74,7 \mathrm{aA}$ \\
Ác. Tartárico $\left(\mathrm{g} \mathrm{L}^{-1}\right)$ & $5,1 \mathrm{aA}$ & $4,9 \mathrm{aA}$ & $5,47 \mathrm{aA}$ & $5,12 \mathrm{aA}$ & $5,38 \mathrm{aA}$ & $5,00 \mathrm{bA}$ \\
Ác. Málico $\left(\mathrm{g} \mathrm{L}^{-1}\right)$ & $2,7 \mathrm{aB}$ & $3,1 \mathrm{aB}$ & $3,75 \mathrm{aA}$ & $3,59 \mathrm{aA}$ & $2,80 \mathrm{aB}$ & $3,17 \mathrm{aAB}$ \\
pH & $3,2 \mathrm{bB}$ & $3,5 \mathrm{aB}$ & $3,33 \mathrm{aA}$ & $3,39 \mathrm{aC}$ & $3,39 \mathrm{bA}$ & $3,58 \mathrm{aA}$ \\
Rendimento em Mosto $(\%)$ & $48,6 \mathrm{aA}$ & $45,1 \mathrm{bA}$ & $42,13 \mathrm{aB}$ & $40,36 \mathrm{bB}$ & $44,87 \mathrm{aA}$ & $42,04 \mathrm{bB}$ \\
\hline
\end{tabular}

*Médias (representam a média de três repetições) na linha seguidas pela mesma letra minúscula (entre os tratamentos coberto e testemunha) ou maiúscula (entre as safras em cada tratamento) não diferem entre si, de acordo com teste de Tukey, ao nível de 5\% de probabilidade de erro.

**Diferença de dez dias entre a primeira e a segunda colheita da safra de 2007.

TABELA 2 - Composição físico-química de vinhos da cultivar (Vitis vinifera L.) Moscato Giallo conduzida em "Y", cultivada com cobertura plástica (A1) e sem cobertura (A2), na colheita das safras de $2006(\mathrm{Pu})$ e em 2007, precoce (P1) e tardia (P2). Flores da Cunha-RS.

\begin{tabular}{lcccccc}
\hline \multirow{2}{*}{ Análises } & \multicolumn{2}{c}{ Safra 2006 (Pu) } & \multicolumn{2}{c}{ Safra 2007 (P1)** } & \multicolumn{2}{c}{ Safra $2007(\mathrm{P} 2)^{* *}$} \\
\cline { 2 - 7 } & $\begin{array}{c}\text { Coberto } \\
(\mathrm{A} 1)\end{array}$ & $\begin{array}{c}\text { Descoberto } \\
(\mathrm{A} 2)\end{array}$ & $\begin{array}{c}\text { Coberto } \\
(\mathrm{A} 1)\end{array}$ & $\begin{array}{c}\text { Descoberto } \\
(\mathrm{A} 2)\end{array}$ & $\begin{array}{c}\text { Coberto } \\
(\mathrm{A} 1)\end{array}$ & $\begin{array}{c}\text { Descoberto } \\
(\mathrm{A} 2)\end{array}$ \\
\hline Densidade & $0,992 \mathrm{aA} *$ & $0,964 \mathrm{aA}$ & $0,992 \mathrm{aA}$ & $0,992 \mathrm{aA}$ & $0,991 \mathrm{aA}$ & $0,992 \mathrm{aA}$ \\
Álcool $(\% \mathrm{v} / \mathrm{v})$ & $10,20 \mathrm{bB}$ & $11,11 \mathrm{aA}$ & $11,02 \mathrm{aA}$ & $11,39 \mathrm{aA}$ & $11,64 \mathrm{aA}$ & $11,41 \mathrm{aA}$ \\
Acidez total $\left(\mathrm{meq} \mathrm{L}^{-1}\right)$ & $76,0 \mathrm{aA}$ & $54,7 \mathrm{bB}$ & $74,66 \mathrm{aA}$ & $74,66 \mathrm{aA}$ & $70,66 \mathrm{aA}$ & $68,66 \mathrm{aA}$ \\
Acidez volátil $\left(\mathrm{meq} \mathrm{L}^{-1}\right)$ & $3,3 \mathrm{bA}$ & $8,0 \mathrm{aA}$ & $4,0 \mathrm{aA}$ & $7,0 \mathrm{aA}$ & $5,0 \mathrm{aA}$ & $6,3 \mathrm{aA}$ \\
$\mathrm{pH}$ & $3,12 \mathrm{bB}$ & $3,6 \mathrm{aA}$ & $3,3 \mathrm{bA}$ & $3,4 \mathrm{aB}$ & $3,3 \mathrm{bA}$ & $3,7 \mathrm{aA}$ \\
Extrato seco $\left(\mathrm{g} \mathrm{L}^{-1}\right)$ & $14,07 \mathrm{aB}$ & $14,23 \mathrm{aB}$ & $15,6 \mathrm{bA}$ & $17,0 \mathrm{aA}$ & $14,8 \mathrm{bB}$ & $17,3 \mathrm{aA}$ \\
Açúcares redutores $\left(\mathrm{g} \mathrm{L}^{-1}\right)$ & $1,08 \mathrm{aB}$ & $1,26 \mathrm{aA}$ & $1,7 \mathrm{aA}$ & $1,4 \mathrm{aA}$ & $1,2 \mathrm{aAB}$ & $1,2 \mathrm{aA}$ \\
Cinzas $\left(\mathrm{g} \mathrm{L}^{-1}\right)$ & $1,1 \mathrm{bB}$ & $1,8 \mathrm{aB}$ & $1,6 \mathrm{aA}$ & $1,6 \mathrm{aB}$ & $1,4 \mathrm{bA}$ & $2,5 \mathrm{aA}$ \\
Densidade Óptica $420 \mathrm{~nm}$ & $0,059 \mathrm{bA}$ & $0,129 \mathrm{aA}$ & $0,049 \mathrm{aA}$ & $0,050 \mathrm{aB}$ & $0,061 \mathrm{aA}$ & $0,063 \mathrm{aB}$ \\
\hline
\end{tabular}

*Médias (representam a média de três microvinificações) na linha seguidas pela mesma letra minúscula (entre os tratamentos coberto e testemunha) ou maiúscula (entre as safras em cada tratamento) não diferem entre si, de acordo com teste de Tukey, ao nível de 5\% de probabilidade de erro.

**Diferença de dez dias entre a primeira e a segunda colheita da safra de 2007.

TABELA 3- Compostos voláteis de vinhos da cultivar (Vitis vinifera L.) Moscato Giallo conduzida em "Y”, cultivada com cobertura plástica (A1) e sem cobertura (A2), na colheita das safras de 2006 $(\mathrm{Pu})$ e em 2007, precoce (P1) e tardia (P2). Flores da Cunha-RS.

\begin{tabular}{ccccccc}
\hline \multirow{2}{*}{$\begin{array}{c}\text { Compostos voláteis } \\
(\mathrm{mg.L}-1)\end{array}$} & \multicolumn{2}{c}{ Safra $2006(\mathrm{Pu})$} & \multicolumn{2}{c}{ Safra $2007(\mathrm{P} 1)^{* *}$} & \multicolumn{2}{c}{ Safra 2007 (P2)** } \\
\cline { 2 - 7 } & $\begin{array}{c}\text { Coberto } \\
(\mathrm{A} 1)\end{array}$ & $\begin{array}{c}\text { Descoberto } \\
(\mathrm{A} 2)\end{array}$ & $\begin{array}{c}\text { Coberto } \\
(\mathrm{A} 1)\end{array}$ & $\begin{array}{c}\text { Descoberto } \\
(\mathrm{A} 2)\end{array}$ & $\begin{array}{c}\text { Coberto } \\
(\mathrm{A} 1)\end{array}$ & $\begin{array}{c}\text { Descoberto } \\
(\mathrm{A} 2)\end{array}$ \\
\hline Aldeído Acético & $51,3 \mathrm{aB} *$ & $44,4 \mathrm{aA}$ & $49,8 \mathrm{bA}$ & $73,0 \mathrm{aA}$ & $53,1 \mathrm{aAA}$ & $59,8 \mathrm{aA}$ \\
Acetato de Etila & $23,5 \mathrm{bA}$ & $38,2 \mathrm{aB}$ & $42,3 \mathrm{bA}$ & $56,6 \mathrm{aA}$ & $45,9 \mathrm{bA}$ & $65,6 \mathrm{aA}$ \\
Metanol & $25,8 \mathrm{aA}$ & $30,8 \mathrm{aA}$ & $16,4 \mathrm{aB}$ & $18,5 \mathrm{aB}$ & $22,8 \mathrm{aA}$ & $26,7 \mathrm{aA}$ \\
1-Propanol & $8,1 \mathrm{aB}$ & $11,6 \mathrm{aA}$ & $14,1 \mathrm{aA}$ & $22,5 \mathrm{aA}$ & $9,6 \mathrm{bA}$ & $27,9 \mathrm{aA}$ \\
2-Metil-1-propanol & $12,1 \mathrm{aB}$ & $19,5 \mathrm{aA}$ & $14,1 \mathrm{aA}$ & $14,3 \mathrm{aA}$ & $12,2 \mathrm{aB}$ & $14,2 \mathrm{aA}$ \\
2-Metil-1- butanol & $22,6 \mathrm{aA}$ & $25,1 \mathrm{aA}$ & $26,5 \mathrm{aA}$ & $39,9 \mathrm{aA}$ & $32,7 \mathrm{aA}$ & $23,5 \mathrm{bA}$ \\
3-Metil-1-butanol & $120,4 \mathrm{aA}$ & $128,4 \mathrm{aA}$ & $143,6 \mathrm{aA}$ & $121,7 \mathrm{bA}$ & $149,7 \mathrm{aA}$ & $126,3 \mathrm{bA}$ \\
Soma Álcoois Sup. & $163,2 \mathrm{bB}$ & $184,5 \mathrm{aB}$ & $198,3 \mathrm{aA}$ & $198,3 \mathrm{aA}$ & $204,1 \mathrm{aA}$ & $191,9 \mathrm{aA}$ \\
\hline
\end{tabular}

*Médias (representam a média de três microvinificações) na linha seguidas pela mesma letra minúscula (entre os tratamentos coberto e testemunha) ou maiúscula (entre as safras em cada tratamento) não diferem entre si, de acordo com teste de Tukey, ao nível de 5\% de probabilidade de erro.

**Diferença de dez dias entre a primeira e a segunda colheita da safra de 2007. 
TABELA 4 - Teores de minerais de vinhos da cultivar (Vitis vinifera L.) Moscato Giallo conduzida em "Y", cultivada com cobertura plástica (A1) e sem cobertura (A2), na colheita das safras de 2006 $(\mathrm{Pu})$ e em 2007, precoce (P1) e tardia (P2). Flores da Cunha-RS.

\begin{tabular}{ccccccc}
\hline \multirow{2}{*}{ Mineral } & \multicolumn{2}{c}{ Safra 2006 $(\mathrm{Pu})$} & \multicolumn{2}{c}{ Safra $2007(\mathrm{P} 1)^{* *}$} & \multicolumn{2}{c}{ Safra $2007(\mathrm{P} 2)^{* *}$} \\
\cline { 2 - 6 } & $\begin{array}{c}\text { Coberto } \\
(\mathrm{A} 1)\end{array}$ & $\begin{array}{c}\text { Descoberto } \\
(\mathrm{A} 2)\end{array}$ & $\begin{array}{c}\text { Coberto } \\
(\mathrm{A} 1)\end{array}$ & $\begin{array}{c}\text { Descoberto } \\
(\mathrm{A} 2)\end{array}$ & Coberto (A1) & $\begin{array}{c}\text { Descoberto } \\
(\mathrm{A} 2)\end{array}$ \\
\hline $\mathrm{P}\left(\mathrm{mg} \mathrm{L}^{-1}\right)$ & $35,3 \mathrm{bB} *$ & $82,5 \mathrm{aB}$ & $147,6 \mathrm{aA}$ & $156,8 \mathrm{aA}$ & $195,6 \mathrm{aA}$ & $158,2 \mathrm{aA}$ \\
$\mathrm{K}\left(\mathrm{mg} \mathrm{L}^{-1}\right)$ & $495,9 \mathrm{bB}$ & $820,0 \mathrm{aA}$ & $1122,4 \mathrm{aA}$ & $1064,6 \mathrm{aA}$ & $1264,4 \mathrm{aA}$ & $1205,9 \mathrm{aA}$ \\
$\mathrm{Ca}\left(\mathrm{mg} \mathrm{L}^{-1}\right)$ & $38,9 \mathrm{aB}$ & $39,2 \mathrm{aB}$ & $69,4 \mathrm{aA}$ & $60,6 \mathrm{aA}$ & $64,2 \mathrm{aA}$ & $56,5 \mathrm{aAB}$ \\
$\mathrm{Mg}\left(\mathrm{mg} \mathrm{L}^{-1}\right)$ & $44,7 \mathrm{bB}$ & $51,9 \mathrm{aB}$ & $139,6 \mathrm{aA}$ & $131,1 \mathrm{aAB}$ & $165,9 \mathrm{aA}$ & $142,0 \mathrm{aA}$ \\
$\mathrm{Na}\left(\mathrm{mg} \mathrm{L}^{-1}\right)$ & $14,4 \mathrm{bB}$ & $15,1 \mathrm{aB}$ & $37,7 \mathrm{aA}$ & $46,8 \mathrm{aA}$ & $37,6 \mathrm{aA}$ & $24,9 \mathrm{aB}$ \\
$\mathrm{Fe}\left(\mathrm{mg} \mathrm{L}^{-1}\right)$ & $0,4 \mathrm{aA}$ & $0,4 \mathrm{aA}$ & $1,6 \mathrm{aA}$ & $1,1 \mathrm{aA}$ & $1,1 \mathrm{aA}$ & $0,8 \mathrm{aA}$ \\
$\mathrm{Cu}\left(\mathrm{mg} \mathrm{L}^{-1}\right)$ & $0,1 \mathrm{aA}$ & $0,2 \mathrm{aA}$ & $1,2 \mathrm{aA}$ & $0,3 \mathrm{aA}$ & $0,3 \mathrm{aA}$ & $0,2 \mathrm{aA}$ \\
$\mathrm{Zn}\left(\mathrm{mg} \mathrm{L}^{-1}\right)$ & $0,1 \mathrm{aB}$ & $0,3 \mathrm{aB}$ & $0,6 \mathrm{aA}$ & $0,6 \mathrm{aA}$ & $0,7 \mathrm{aA}$ & $0,4 \mathrm{aAB}$ \\
$\mathrm{Mn}\left(\mathrm{mg} \mathrm{L}^{-1}\right)$ & $1,0 \mathrm{bA}$ & $1,2 \mathrm{aA}$ & $3,2 \mathrm{aA}$ & $3,0 \mathrm{aA}$ & $1,7 \mathrm{aA}$ & $2,7 \mathrm{aA}$ \\
$\mathrm{Rb}\left(\mathrm{mg} \mathrm{L}^{-1}\right)$ & $2,7 \mathrm{bB}$ & $3,5 \mathrm{aB}$ & $5,2 \mathrm{aAB}$ & $7,2 \mathrm{aA}$ & $7,6 \mathrm{aA}$ & $7,4 \mathrm{aA}$ \\
$\mathrm{Li}\left(\mu \mathrm{g} \mathrm{L}^{-1}\right)$ & $4,8 \mathrm{aA}$ & $3,9 \mathrm{aA}$ & $3,9 \mathrm{aA}$ & $3,8 \mathrm{aA}$ & $5,5 \mathrm{aA}$ & $4,4 \mathrm{aA}$ \\
\hline
\end{tabular}

*Médias (representam a média de três microvinificações) na linha seguidas pela mesma letra minúscula (entre os tratamentos coberto e testemunha) ou maiúscula (entre as safras em cada tratamento) não diferem entre si, de acordo com teste de Tukey, ao nível de 5\% de probabilidade de erro.

**Diferença de dez dias entre a primeira e a segunda colheita da safra de 2007.

\section{CONCLUSÕES}

1-A uva da cultivar Moscato Giallo, produzida sob cobertura plástica, apresenta maior rendimento de mosto. Porém, devido ao atraso da maturação, apresenta menor concentração de açúcares, e o vinho apresenta menor graduação alcoólica; entretanto, com reduzido teor de acetato de etila e acidez volátil.

2-O prolongamento da maturação da uva sob cobertura plástica determina atraso na data de colheita, para que seja atingida a mesma concentração de açúcar no mosto e graduação alcoólica no vinho.

\section{REFERÊNCIAS}

AERNY, J. Définition de la qualité de la vendange. Revue Suisse de Viticulture, Arboriculture, Horticulture, Nyon, v.17, n.4, p.219-223, 1985.

BOULTON, R. The general relationship between potassium, sodium and $\mathrm{pH}$ in grape juice and wine. American Journal of Enology and Viticulture, Davis, v.31, n.2, p.182-186, 1980.

CARDOSO, L.S.; BERGAMASCHI, H.; COMIRAM, F.; CHAVARRIA, G.; MARODIN, G.A.B.; DALMAGO, G. A.; SANTOS, H.P.; MANDELLI, F. Alterações micrometeorológicas em vinhedos pelo uso de coberturas de plástico. Pesquisa Agropecuária Brasileira, Brasília, v.43, p.441-447, 2008.
CHAVARRIA, G.; SANTOS, H.P.; SÔNEGO, O.R.; MARODIN, G.A.B.; BERGAMASCHI, H.; CARDOSO, L.S. Incidência de doenças e necessidade de controle em cultivo protegido de videira. Revista Brasileira de Fruticultura, Jaboticabal, v.29, n.3, p.477-482, 2007.

CHAVARRIA, G., SANTOS, H.P.; MANDELLI, F.; MARODIN, G.A.B.; BERGAMASCHI, H.; CARDOSO, L.S. Caracterização fenológica e requerimento térmico da cultivar Moscato Giallo sob cobertura plástica. Revista Brasileira de Fruticultura, Jaboticabal, v.31, n.1, p.119-126, 2008a.

CHAVARRIA, G.; SANTOS, H.P.; ZANUS, M.C.; ZORZAN, C.; MARODIN, G.A.B. Caracterização físico-química do mosto e do vinho Moscato Giallo em videiras cultivadas sob cobertura de plástico. Pesquisa Agropecuária Brasileira, Brasília, v.43, n.7, p. 911-916, 2008 b.

CHAVARRIA, G.; SANTOS, H.P.; FELIPPETO, J.; MARODIN, G.A.B.; BERGAMASCHI, H.; CARDOSO, L.S.; FIALHO, F.B. Relações hídricas e trocas gasosas em vinhedo sob cobertura plástica. Revista Brasileira de Fruticultura, Jaboticabal, v.30, p.1022-1029, 2008c. 
CHAVARRIA, G.; SANTOS, H.P.; MANDELLI, F.; MARODIN, G.A.B.; BERGAMASCHI, H.; CARDOSO, L.S. Potencial produtivo de videiras cultivadas sob cobertura de plástico. Pesquisa Agropecuária Brasileira, Brasília, v.44, n.2, p.141-147, 2009.

JACKSON R.S. Wine Science: principles, practices, perception. $2^{\text {nd }}$ ed. San Diego: Academic Press, 2000. 654p.

MAARSE, H.; SLUMP, A.C.; TAS, A.C.; SCHAEFER, J. Classification of wines according to type and region based on their composition. Zeitschrift fur Lebensmittel - Untersuchung und - Forschung, Berlin, v.184 p.198-203, 1987.

MASLE, J.; FARQUHAR, G.D.; WONG, S.C. Transpiration ratio and plant mineral content are related among genotypes of a range of species. Australian Journal of Plant Physiology, Melbourne, v.19, n.6, p. $709-721,1992$.

MENEGUZZO, J.; RIZZON, L.A.; AYUB, M.A.Z.; MIELE, A. Efeito de Botrytis cinerea na composição do vinho Gewürztramine. Ciência e Tecnologia de Alimentos, Campinas, v.26, n.3, p.527-532, 2006.

MIELE, A.; RIZZON, L.A. Efeito de elevadas produtividades do vinhedo nas características físicoquímicas e sensoriais do vinho Merlot, Ciência Rural, Santa Maria, v.36, n.1, p.271-278, 2006.
MULLINS, M.G.; BOUQUET, A.; WILLIAMS, L.E. Biology of the grapevine. New York: Cambridge University Press, 1992. 239p.

RIZZON, L. A.; MIELE, A. Avaliação da Cv. Cabernet Franc para elaboração de vinho tinto. Ciência e Tecnologia de Alimentos, v. 21, n. 2, p. 249-255, 2001.

RIZZON, L.A.; SGANZERLA, V.A.A. Ácidos tartárico e málico no mosto de uva em Bento Gonçalves-RS. Ciência Rural, Santa Maria, v.37, n.3, p.911-914, 2007.

RIZZON, L.; ZANUS, M.C.; MIELE, A. Evolução da acidez durante a vinificação de uvas tintas de três regiões vitícolas de Rio Grande do Sul. Ciência e Tecnologia de Alimentos, Campinas, v.18, n.2, p.149-156, 1998.

SÔNEGO, O. R.; GARRIDO, L. da R.; GRIGOLETTI JÚNIOR, A. Doenças fúngicas. In: FAJARDO, T. V. M. Uva para processamento: fitossanidade. Brasília: Embrapa Informação Tecnológica, 2003. p. 11-44. (Série Frutas do Brasil, 35).

SÔNEGO, O.R.; GARRIDO, L. da R.; GRIGOLETTI JÚNIOR. Principais doenças fúngicas da videira no Sul do Brasil. Bento Gonçalves: Embrapa Uva e Vinho, 2005. 32 p. (Circular Técnica, 56) 